\title{
Metodologia para a elaboração de estrutura salarial em instituições de ensino
}

\author{
Methodology for establishing salary structure in educational organizations \\ Méthodologie pour l'élaboration de la structure salariale dans les établissements d'enseignement
}

\author{
Selma Maria Assis Dias ${ }^{1}$ \\ Universidade de São Paulo \\ Rosebelly Nunes Marques ${ }^{2}$ \\ Universidade de São Paulo \\ Flavio Henrique Mendes ${ }^{3}$ \\ Universidade de São Paulo
}

Resumo: Estabelecer uma estrutura salarial que permita que uma organização alcance seus objetivos e, ao mesmo tempo, seja compatível com o mercado é sempre um grande desafio. Salários justos aumentam os níveis de motivação, retêm talentos e reforçam o comprometimento dos colaboradores. Esta pesquisa propõe uma metodologia indexada para o estabelecimento de valores salariais para os cargos de uma instituição de ensino, considerando os pisos salariais das respectivas classes trabalhistas e as médias salariais praticadas no mercado. Foram criados Fatores de Experiência, Fatores Mínimos de Remuneração e Fatores finais de Remuneração. Ao estabelecer-se o valor mínimo ou máximo que a instituição deseja pagar a seus colaboradores, apurou-se a estrutura salarial para todos os cargos da instituição.

Palavras-chave: Plano de carreira, cargos e salários. Médias salariais. Salários em escolas privadas. Remuneração por cargo.

Abstract: It is a great challenge to establish salary structures that allows an organization to reach its goals and, at the same time, are compatible with the market. Fair wages increases motivation levels, retains talent, and strengthens the commitment of employees. This paper proposes an indexed methodology for the establishment of salary values for all positions of an educational organization, considering the wage levels of the respective working parties and the average salaries practiced in the market. We created indexes of Experience, Minimum Salary and Final Salary. When determining the minimum or maximum amount an organization is willing to pay to its employees, the pay scale for all positions of the institution was automatically determined.

Keywords: Career plan. Salaries and wages, average salary. Salaries in private school. Pay scales.

\footnotetext{
${ }^{1}$ Especialista em Gestão Escolar pela Universidade de São Paulo (USP), Escola Superior de Agricultura "Luiz de Queiroz").E-mail: selmadias.esteves@outlook.com. Lattes: http://lattes.cnpq.br/5167436418028357.

${ }^{2}$ Doutora em Educação Escolar. Docente da Universidade de São Paulo (USP), Escola Superior de Agricultura "Luiz de Queiroz. E-mail: rosebelly.esalq@usp.br. Lattes: http://lattes.cnpq.br/7921735904003583. ORCID: https://orcid.org/0000-0002-8726-3211.

${ }^{3}$ Universidade de São Paulo (USP), Escola Superior de Agricultura "Luiz de Queiroz". Mestre em Ciências na USP. E-mail: friquemendes@usp.br. Lattes: http://lattes.cnpq.br/3191612135327796. ORCID: https://orcid.org/0000-0002-7628-4850.
} 
Résumé: Établir une structure salariale permettant à une organisation d'atteindre ses objectifs tout en étant compatible avec le marché est toujours un défi majeur. Des salaires équitables augmentent les niveaux de motivation, retiennent les talents et renforcent l'engagement des employés. Ce document propose une méthodologie indexée pour l'établissement des valeurs salariales pour les postes d'un établissement d'enseignement, en tenant compte des niveaux de salaire des différentes classes de travail et des salaires moyens pratiqués sur le marché. Des facteurs d'expérience, de compensation minimum et de compensation finale ont été créés. En établissant le montant minimum ou maximum que l'institution souhaite verser à ses employés, la structure salariale de tous les postes de l’institution a été déterminée.

Mots-clés: Plan de carrière, postes et salaires. Salaires moyens. Salaires dans les écoles privées. Rémunération par poste.

Recebido em: 3 de setembro de 2019 Aceito em: 07 de janeiro 2020

\section{Introdução}

O salário justo e compatível é um grande fator de motivação dentro de uma equipe, no contexto da transparência entre os membros (DRUCKER, 1974). A literatura diverge quanto à remuneração dos professores ser adequada ou não, contrapondo duas grandes áreas com visões diferentes: educação e economia (PEREIRA; ALVES, 2015). Vários autores questionam a existência de uma relação direta entre incentivo financeiro e desempenho do professor (PALAZZO; GOMES, 2009). Desta maneira, alcançar uma divisão igualitária de verbas dentro de uma organização se impõe como um desafio, pois depende de múltiplos fatores. Pelos seus efeitos e consequências, a elaboração de um plano de remuneração requer muitos cuidados, pois exerce forte impacto nas pessoas e no desempenho da organização (WALLACE, 1991).

O incentivo à promoção ao plano de carreiras dos profissionais da educação brasileira é previsto na Lei n 13.005/2014, que aprova o Plano Nacional da Educação (PNE), e em seu artigo $2^{\circ}$, parágrafo IX, destaca a "valorização dos (as) profissionais da educação” (BRASIL, 2014). A meta 18 do PNE integra essa diretriz e prevê no prazo de dois anos a existência dos planos de carreira aos profissionais da educação básica e superior pública de todos os sistemas de ensino, tomando como referência o piso salarial nacional profissional, definido em lei federal, nos termos do inciso VIII do art. 206 da Constituição Federal (BRASIL, 1988).

Muitas vezes os professores são contratados para uma jornada de trabalho de poucas horas e necessitam acumular empregos ou funções em outras escolas, colaborando para a baixa atratividade da profissão no Brasil. Como elaborar tais planos de carreira? Quais critérios devem ser levados em consideração? Devido aos itens avaliados pelo Ministério da Educação (MEC) para a pontuação e classificação dos cursos no Brasil, vê-se que a maioria dos planos de 
carreira do magistério priorizam critérios como titulação, anos de experiência em sala de aula e quantidade de publicações no currículo do docente como fatores de remuneração (PALAZZO, 2009). Entretanto, pesquisas comprovam a ausência de relação entre tais critérios com o resultado almejado - o bom rendimento dos alunos. Mello e Souza (2005) afirma que maiores salários normalmente estão associados com o tempo de experiência na profissão, bem como com a titulação do docente, critérios estes que se mostraram irrelevantes para o desempenho dos alunos. Os autores ainda sugerem que um sistema de bonificação conectado ao desempenho dos alunos seria algo mais produtivo.

Países com educação de qualidade desenvolvem políticas de valorização das carreiras dos professores. Andreas Schleicher, idealizador do ranking Pisa, organizado pela Organização para a Cooperação e Desenvolvimento Econômico (OCDE), o qual é responsável por avaliar o desempenho de jovens de 15 anos em ciências, matemática e leitura em 75 países, afirma que “a qualidade da educação de um país nunca será maior que a qualidade dos seus professores”. A OCDE analisou políticas para professores de 19 países que, além de obterem aproveitamento satisfatório no Pisa, apresentaram resultados similares na qualidade do ensino para alunos ricos e pobres, identificando alguns fatores em comum: testes de admissão de professores rigorosos, recrutamento dos melhores alunos do ensino médio para se tornarem professores, experiência prática como parte na formação dos professores, especialização na área do ensino, desafios e educação continuada e, por fim, plano de carreira e bons salários. A OCDE destaca que os países com melhor desempenho no Pisa pagam maiores salários aos professores que a renda per capita nacional (BBC NEWS, 2018).

Tendo em vista os baixos salários e os recursos financeiros escassos, a equidade nos salários dos trabalhadores torna-se imprescindível. Cada membro da equipe escolar precisa sentir-se valorizado, ao fazer parte do todo (SILVA; LEÃO, 2018). Quanto mais cedo a elaboração e implantação de um sistema remunerativo justo, dentro da organização, maiores as chances de proporcionar tratamento equitativo a todas as pessoas envolvidas.

Segundo Chiavenato (2014), o salário é uma contraprestação pelo trabalho de uma pessoa à organização. A pessoa empenha parte de si mesma, de seu esforço e de sua vida em troca do dinheiro - elemento simbólico e intercambiável -, comprometendo-se a uma atividade cotidiana e a um padrão de desempenho na organização.

Para os funcionários, o salário constitui a fonte de renda que proporciona o poder aquisitivo. $\mathrm{O}$ volume de dinheiro que a pessoa ganha define seu padrão de vida, servindo também como indicador de poder e prestígio, o que influencia seus sentimentos de autoestima. Deste modo, a remuneração não somente afeta as pessoas sob o ponto de vista econômico, mas também psicológico e sociológico (WALLACE; FAY, 1983). 
Para a organização, o salário representa ao mesmo tempo um investimento e um custo. Investimento porque representa a aplicação de dinheiro em um fator de produção - o trabalho - agregando valor ao produto ou ao serviço, gerando maior retorno a curto e médio prazo. Custo porque o salário reflete no preço do produto ou serviço final (CHIAVENATO, 2014).

A implantação de uma estrutura de salários equitativa e justa atrai e retém talentos, incentiva bons desempenhos, mantém os níveis de motivação, reforça o comprometimento pessoal e as relações intergrupais, promove mudanças de baixas para altas performances, com o objetivo de receber recompensas, deixando claro que há uma relação entre mérito e recompensa, favorecendo a produtividade (MILKOVICK; BOUDREAU, 1994).

O desenho de um sistema de remuneração oferece dois grandes desafios: além de capacitar a organização a alcançar seus objetivos estratégicos, deve também ser moldado e ajustado às características únicas da organização e do ambiente externo que a envolvem (CARROL, 1987).

O objetivo principal da remuneração é criar um sistema de recompensas que seja equitativo tanto para a organização quanto para os funcionários. Uma política salarial deve atender simultaneamente a sete critérios para ser eficaz: adequada, equitativa, balanceada, ter eficácia quanto a custos, segura, incentivadora e aceitável para os funcionários (PATTON, 1977).

Para estabelecer e manter estruturas salariais equitativas, é necessário estabelecer duas formas de equilíbrio: o equilíbrio interno, o qual busca uma consistência interna entre os salários em relação aos cargos dentro da organização, exigindo uma estrutura salarial justa, balanceada e bem dosada; e o equilíbrio externo, o qual busca uma consistência externa dos salários em relação aos mesmos cargos de outras organizações que atuam no mercado de trabalho, buscando uma estrutura salarial compatível com o mercado (CHIAVENATO, 2010).

Por fim, existem nove critérios básicos que devem ser considerados para a criação de um plano de remuneração: equilíbrio interno x equilíbrio externo, remuneração fixa ou remuneração variável, desempenho ou tempo de casa, remuneração do cargo ou remuneração das competências, igualitarismo ou elitismo, remuneração abaixo ou acima do mercado, prêmios monetários ou não monetários, remuneração aberta ou remuneração confidencial, centralização ou descentralização das decisões salariais (CHIAVENATO, 2014).

Diante da importância do estabelecimento de um sistema de remuneração justo e equitativo dentro de instituições de ensino privadas e da escassez na literatura acadêmica de métodos para a elaboração dos mesmos, o objetivo desta pesquisa consistiu em propor uma metodologia indexada para o estabelecimento de valores salariais equitativos para todos os cargos dentro de uma instituição escolar (equilíbrio interno), levando-se em consideração os pisos salariais das respectivas classes trabalhistas e as médias salariais praticadas no mercado (equilíbrio externo). 


\section{Metodologia}

Este trabalho caracterizou-se por uma pesquisa documental realizada por meio da análise de Convenções Coletivas de Trabalho (CCT) de professores e de auxiliares administrativos escolares, bem como os seguintes sites: Site Nacional de Empregos (SINE), Trabalha Brasil e Banco Nacional de Empregos (BNE).

Para efeito de definição, estrutura salarial é um conjunto de faixas salariais relacionadas com os diferentes cargos existentes na organização. Nos sistemas funcionais, o conjunto de atividades, compreendidas em um cargo, funciona como base para definição da remuneração. Essa abordagem supõe que o valor de um cargo pode ser determinado pelos valores praticados no mercado, proporcionando uma equidade externa, facilitando a atração e retenção dos funcionários (CHIAVENATO, 2014).

Para a determinação dos cargos de uma organização escolar, foram analisadas as Convenções Coletivas de Trabalho (CCT) dos Auxiliares de Educação de diversos estados brasileiros. Em sua maioria, as CCT estabelecem um piso mínimo para todos os cargos de auxiliares escolares, não enumerando cargos. Para efeitos de praticidade, adotou-se como referência de cargos, a CCT do Sindicato dos Auxiliares de Administração Escolar do Estado do Rio de Janeiro (SAAERJ) 2018/2019, a qual aponta cargos e, segundo Chiavenato, utiliza o método de escalonamento simultâneo (CHIAVENATO, 2014), agregando os cargos dos auxiliares de administração escolar em faixas de piso salarial mínimo (Tabela 1). Os pisos salariais foram estabelecidos pela CCT da SAAERJ para os empregados dos estabelecimentos de Educação Infantil (creche e pré-escola), Ensino Fundamental ( $1^{\circ}$ ao $9^{\circ}$ ano e Ensino Médio (educação geral, técnica integrada/concomitante/subsequente), por 44 (quarenta e quatro) horas semanais e 220 (duzentas e vinte) horas mensais, a partir de 1 de março de 2018. 
Tabela 1: Pisos salariais da CCT da SAAERJ 2018/2019

\begin{tabular}{|c|c|c|}
\hline Nível na CCT & Cargo & $\begin{array}{c}\text { Piso salarial mínimo } \\
(\mathrm{R} \$)\end{array}$ \\
\hline $1^{\circ}$ Nível & $\begin{array}{l}\text { Auxiliar de serviços gerais } \\
\text { Auxiliar de cozinha } \\
\text { Copeiro } \\
\text { Faxineiro } \\
\text { Servente } \\
\text { Serviços de conservação e manutenção }\end{array}$ & $1.042,93$ \\
\hline $2^{\circ}$ Nível & $\begin{array}{l}\text { Porteiro } \\
\text { Inspetor de alunos } \\
\text { Cozinheiro } \\
\text { Auxiliar administrativo }\end{array}$ & $1.052,56$ \\
\hline $3^{\circ}$ Nível & $\begin{array}{l}\text { Auxiliar de secretaria } \\
\text { Auxiliar de Educação Infantil } \\
\text { Auxiliar de Ensino Fundamental } \\
\text { Auxiliar de Ensino Médio } \\
\text { Assistente de biblioteca } \\
\text { Coordenador de turno }\end{array}$ & 1.105 .42 \\
\hline $4^{\mathrm{o}}$ Nível & $\begin{array}{l}\text { Secretária escolar } \\
\text { Gerente }\end{array}$ & $1.123,44$ \\
\hline $5^{\circ}$ Nível & $\begin{array}{l}\text { Coordenador pedagógico } \\
\text { Coordenador de área } \\
\text { Orientador educacional } \\
\text { Nutricionista } \\
\text { Psicólogo } \\
\text { Bibliotecário } \\
\end{array}$ & $2.162,78$ \\
\hline $6^{\circ}$ Nível & $\begin{array}{l}\text { Diretor pedagógico } \\
\text { Diretor administrativo } \\
\text { Diretor financeiro } \\
\text { Diretor comercial } \\
\text { Diretor geral } \\
\text { Vice-diretor } \\
\end{array}$ & 2.403,09 \\
\hline
\end{tabular}

Fonte: Os autores

\section{Resultados e Discussão}

Buscando-se entender como os anos de experiência profissional afetam o valor da remuneração no mercado de trabalho, foram analisados os dados do site Trabalha Brasil. Esta fonte de dados considera os currículos cadastrados no Banco Nacional de Empregos (BNE) e as contribuições salariais do site Salário BR nos últimos doze meses.

As médias salariais pesquisadas levam em consideração tanto a experiência do trabalhador quanto o porte da empresa. Quanto à experiência do trabalhador, é considerado Trainee de 0 a 2 anos de experiência; Júnior, de 2 a 4 anos; Pleno, de 4 a 6 anos; Sênior, de 6 a 8 anos e Master, com mais de oito anos de experiência na função. Quanto ao porte da empresa, são consideradas de pequeno porte aquelas que têm uma receita bruta anual até 10,5 milhões de reais e possuem até 499 funcionários; de médio porte aquelas que têm uma receita bruta anual entre 10,5 e 300 milhões 
de reais e que possuem entre 500 e 999 funcionários e de grande porte aquelas que faturam acima de 300 milhões de reais e possuem mais de 999 funcionários.

Para fins deste trabalho, foram coletadas as médias salariais para todos os cargos da CCT da SAAERJ, no dia 01/03/2019, considerando-se uma empresa de pequeno porte, ou seja, aquela com receita bruta anual até 10,5 milhões de reais e menos de 500 funcionários. A fonte utilizada para o cálculo das médias salariais foram os salários pretendidos nos currículos cadastrados no BNE e as contribuições salariais do Salário BR nos últimos doze meses. O resultado obtido encontra-se na Tabela 2.

Tabela 2: Média salarial praticada no mercado para os cargos da CCT da SAAERJ

\begin{tabular}{|c|c|c|c|c|c|c|}
\hline Cargo & $\begin{array}{c}\text { Trainee } \\
\mathrm{R} \$\end{array}$ & $\begin{array}{c}\text { Júnior } \\
\mathrm{R} \$\end{array}$ & $\begin{array}{c}\text { Pleno } \\
\mathrm{R} \$\end{array}$ & $\begin{array}{c}\text { Sênior } \\
\mathrm{R} \$\end{array}$ & $\begin{array}{c}\text { Master } \\
\mathrm{R} \$\end{array}$ & $\begin{array}{l}\text { Amos- } \\
\text { tragem }\end{array}$ \\
\hline Auxiliar de serviços gerais & 889,13 & 978,04 & $1.075,84$ & $1.183,42$ & $1.301,76$ & 134.787 \\
\hline Auxiliar de cozinha & $1.006,28$ & $1.106,91$ & $1.217,60$ & $1.339,36$ & $1.473,30$ & 44.486 \\
\hline Copeiro & 971,73 & $1.068,90$ & $1.175,79$ & $1.293,37$ & $1.422,71$ & 8.612 \\
\hline Faxineiro & 962,48 & $1.058,73$ & $1.164,60$ & $1.281,06$ & $1.409,17$ & 55.101 \\
\hline Servente & 962,48 & $1.058,73$ & $1.164,60$ & $1.281,06$ & $1.409,17$ & 55.101 \\
\hline Serviços de manutenção & $1.117,86$ & $1.229,65$ & $1.352,61$ & $1.487,87$ & $1.636,66$ & 8.742 \\
\hline Porteiro & $1.023,47$ & $1.125,82$ & $1.238,40$ & $1.362,24$ & $1.498,46$ & 58.677 \\
\hline Inspetor de alunos & $1.063,16$ & $1.222,63$ & $1.406,03$ & $1.616,93$ & $1.859,47$ & 4.259 \\
\hline Cozinheiro & $1.185, \mathrm{OO}$ & $1.303,50$ & $1.433,85$ & $1.577,24$ & $1.734,96$ & 24.208 \\
\hline Auxiliar administrativo & 983,02 & $1.130,47$ & $1.300,04$ & $1.495,05$ & $1.719,31$ & 377.854 \\
\hline Auxiliar de secretaria & 973,63 & $1.119,67$ & $1.287,62$ & $1.480,76$ & $1.702,87$ & 4.094 \\
\hline $\begin{array}{l}\text { Auxiliar de Educação } \\
\text { Infantil }\end{array}$ & 963,85 & $1.108,43$ & $1.274,69$ & $1.465,89$ & $1.685,77$ & 20.513 \\
\hline $\begin{array}{l}\text { Auxiliar de Ensino } \\
\text { Fundamental }\end{array}$ & 963,85 & $1.108,43$ & $1.274,69$ & $1.465,89$ & $1.685,77$ & 20.513 \\
\hline Auxiliar de Ensino Médio & 963,85 & $1.108,43$ & $1.274,69$ & $1.465,89$ & $1.685,77$ & 20.513 \\
\hline Assistente de biblioteca & $1.083,59$ & $1.246,13$ & $1.433,05$ & $1.648,01$ & $1.895,21$ & 348 \\
\hline $\begin{array}{l}\text { Coordenador de turno } \\
\text { (auxiliar de coordenação } \\
\text { pedagógica) }\end{array}$ & $1.114,57$ & $1.281,76$ & $1.474,02$ & $1.695,12$ & $1.949,39$ & 4.354 \\
\hline Secretária escolar & 979,32 & $1.224,15$ & $1.530,19$ & $1.912,74$ & $2.390,93$ & 247 \\
\hline $\begin{array}{l}\text { Gerente (encarregado } \\
\text { escolar) }\end{array}$ & 972,11 & $1.263,74$ & $1.642,86$ & $2.135,72$ & $2.776,44$ & 22 \\
\hline Coordenador pedagógico & $2.131,75$ & $2.771,28$ & $3.602,66$ & $4.683,46$ & $6.088,50$ & 3.371 \\
\hline Coordenador de área & $2.131,75$ & $2.771,28$ & $3.602,66$ & $4.683,46$ & $6.088,50$ & 3.371 \\
\hline Orientador educacional & $1.362,40$ & $1.703,00$ & $2.128,75$ & $2.660,94$ & $3.326,18$ & 2.795 \\
\hline Nutricionista & $1.620,34$ & $2.025,42$ & $2.531,77$ & $3.164,71$ & $3.955,89$ & 18.038 \\
\hline Psicólogo & $1.844,06$ & $2.305,07$ & $2.881,34$ & $3.601,68$ & $4.502,10$ & 22.682 \\
\hline Bibliotecário & $1.308,79$ & $1.635,99$ & $2.044,99$ & $2.556,24$ & $3.195,30$ & 2.662 \\
\hline Diretor pedagógico & $2.763,08$ & $3.592,00$ & $4.669,60$ & $6.070,48$ & $7.891,62$ & 220 \\
\hline Diretor administrativo & $5.441,22$ & $7.073,58$ & $9.195,65$ & $11.954,35$ & $15.540,66$ & 310 \\
\hline Diretor financeiro & $7.275,60$ & $9.458,28$ & $12.295,76$ & $15.984,49$ & $20.779,84$ & 213 \\
\hline Diretor comercial & $6.881,47$ & $8.945,91$ & $11.629,68$ & $15.118,58$ & $19.654,15$ & 766 \\
\hline Diretor geral & $3.467,55$ & $4.507,82$ & $5.860,16$ & $7.618,21$ & $9.903,67$ & 294 \\
\hline Vice-diretor & $3.467,55$ & $4.507,82$ & $5.860,16$ & $7.618,21$ & $9.903,67$ & 294 \\
\hline
\end{tabular}


Analisando-se os dados obtidos na Tabela 2, observamos que há um padrão matemático no aumento da remuneração em função dos anos de experiência. Dividindo-se os valores das segunda (Júnior), terceira (Pleno), quarta (Master) e quinta (Sênior) colunas, pelo valor da primeira coluna (Trainee), obtemos o que podemos chamar de "Fatores de Experiência” (Tabela 3).

Tabela 3: Fatores de experiência dos cargos escolares da CCT da SAAERJ 2018/2019

\begin{tabular}{lccccc}
\hline Cargo & Trainee & Júnior & Pleno & Sênior & Master \\
& Fator & Fator & Fator & Fator & Fator \\
\hline Auxiliar de serviços gerais & 1,0000 & 1,1000 & 1,2100 & 1,3310 & 1,4641 \\
Auxiliar de cozinha & 1,0000 & 1,1000 & 1,2100 & 1,3310 & 1,4641 \\
Copeiro & 1,0000 & 1,1000 & 1,2100 & 1,3310 & 1,4641 \\
Faxineiro & 1,0000 & 1,1000 & 1,2100 & 1,3310 & 1,4641 \\
Servente & 1,0000 & 1,1000 & 1,2100 & 1,3310 & 1,4641 \\
Serviços de manutenção & 1,0000 & 1,1000 & 1,2100 & 1,3310 & 1,4641 \\
\hline Porteiro & 1,0000 & 1,1000 & 1,2100 & 1,3310 & 1,4641 \\
Inspetor de alunos & 1,0000 & 1,1500 & 1,3225 & 1,5209 & 1,7490 \\
Cozinheiro & 1,0000 & 1,1000 & 1,2100 & 1,3310 & 1,4641 \\
Auxiliar administrativo & 1,0000 & 1,1500 & 1,3225 & 1,5209 & 1,7490 \\
\hline Auxiliar de secretaria & 1,0000 & 1,1500 & 1,3225 & 1,5209 & 1,7490 \\
Auxiliar de Educação Infantil & 1,0000 & 1,1500 & 1,3225 & 1,5209 & 1,7490 \\
Auxiliar de Ensino Fundamental & 1,0000 & 1,1500 & 1,3225 & 1,5209 & 1,7490 \\
Auxiliar de Ensino Médio & 1,0000 & 1,1500 & 1,3225 & 1,5209 & 1,7490 \\
Assistente de biblioteca & 1,0000 & 1,1500 & 1,3225 & 1,5209 & 1,7490 \\
Coordenador de turno & 1,0000 & 1,1500 & 1,3225 & 1,5209 & 1,7490 \\
\hline Secretária escolar & 1,0000 & 1,2500 & 1,5625 & 1,9531 & 2,4414 \\
Gerente & 1,0000 & 1,3000 & 1,6900 & 2,1970 & 2,8561 \\
\hline Coordenador pedagógico & 1,0000 & 1,3000 & 1,6900 & 2,1970 & 2,8561 \\
Coordenador de área & 1,0000 & 1,3000 & 1,6900 & 2,1970 & 2,8561 \\
Orientador educacional & 1,0000 & 1,2500 & 1,5625 & 1,9531 & 2,4414 \\
Nutricionista & 1,0000 & 1,2500 & 1,5625 & 1,9531 & 2,4414 \\
Psicólogo & 1,0000 & 1,2500 & 1,5625 & 1,9531 & 2,4414 \\
Bibliotecário & 1,0000 & 1,2500 & 1,5625 & 1,9531 & 2,4414 \\
\hline Diretor pedagógico & 1,0000 & 1,3000 & 1,6900 & 2,1970 & 2,8561 \\
Diretor administrativo & 1,0000 & 1,3000 & 1,6900 & 2,1970 & 2,8561 \\
Diretor financeiro & 1,0000 & 1,3000 & 1,6900 & 2,1970 & 2,8561 \\
Diretor comercial & 1,0000 & 1,3000 & 1,6900 & 2,1970 & 2,8561 \\
Diretor geral & 1,0000 & 1,3000 & 1,6900 & 2,1970 & 2,8561 \\
Vice-diretor & 1,0000 & 1,3000 & 1,6900 & 2,1970 & 2,8561 \\
\hline & & & & & \\
\hline & & 1,050 & & &
\end{tabular}

Fonte: Os autores

Seguindo-se o mesmo raciocínio, podemos reduzir os valores de piso salarial da CCT da SAAERJ ao que podemos chamar de "Fatores Mínimos de Remuneração", dividindo-se os valores dos $2^{\circ}, 3^{\circ}, 4^{\circ}, 5^{\circ}$ e $6^{\circ}$ níveis pelo valor do primeiro nível (Tabela 4 ). 
Tabela 4: Fatores Mínimos de Remuneração dos cargos da CCT da SAAERJ

\begin{tabular}{|c|c|c|}
\hline Cargo & Nível na CCT & $\begin{array}{l}\text { Fator mínimo de } \\
\text { remuneração }\end{array}$ \\
\hline Auxiliar de serviços gerais & \multirow{6}{*}{$1^{\circ}$ Nível } & 1,0000 \\
\hline Auxiliar de cozinha & & 1,0000 \\
\hline Copeiro & & 1,0000 \\
\hline Faxineiro & & 1,0000 \\
\hline Servente & & 1,0000 \\
\hline Serviços de conservação e manutenção & & 1,0000 \\
\hline Porteiro & \multirow{4}{*}{$2^{\circ}$ Nível } & 1,0092 \\
\hline Inspetor de alunos & & 1,0092 \\
\hline Cozinheiro & & 1,0092 \\
\hline Auxiliar administrativo & & 1,0092 \\
\hline Auxiliar de secretaria & \multirow{6}{*}{$3^{\circ}$ Nível } & 1,0599 \\
\hline Auxiliar de Educação Infantil & & 1,0599 \\
\hline Auxiliar de Ensino Fundamental & & 1,0599 \\
\hline Auxiliar de Ensino Médio & & 1,0599 \\
\hline Assistente de biblioteca & & 1,0599 \\
\hline Coordenador de turno & & 1,0599 \\
\hline Secretária escolar & \multirow{2}{*}{$4^{\circ}$ Nível } & 1,0772 \\
\hline Gerente & & 1,0772 \\
\hline Coordenador pedagógico & \multirow{6}{*}{$5^{\mathrm{o}}$ Nível } & 2,0738 \\
\hline Coordenador de área & & 2,0738 \\
\hline Orientador educacional & & 2,0738 \\
\hline Nutricionista & & 2,0738 \\
\hline Psicólogo & & 2,0738 \\
\hline Bibliotecário & & 2,0738 \\
\hline Diretor pedagógico & \multirow{6}{*}{$6^{\mathrm{o}}$ Nível } & 2,3042 \\
\hline Diretor administrativo & & 2,3042 \\
\hline Diretor financeiro & & 2,3042 \\
\hline Diretor comercial & & 2,3042 \\
\hline Diretor geral & & 2,3042 \\
\hline Vice-diretor & & 2,3042 \\
\hline
\end{tabular}

Fonte: Os autores

Assim, multiplicando-se os Fatores de Experiência (Tabela 3) pelos Fatores Mínimos de Remuneração (Tabela 4), obtemos os "Fatores Finais de Remuneração" (Tabela 5). 
Tabela 5: Fatores Finais de Remuneração para os cargos da CCT da SAAERJ

\begin{tabular}{|c|c|c|c|c|c|c|}
\hline Cargos & $\begin{array}{l}\text { Nível } \\
\text { CCT }\end{array}$ & Trainee & Júnior & Pleno & Sênior & Master \\
\hline Auxiliar de serviços gerais & \multirow{6}{*}{$1^{\circ}$ Nível } & 1,0000 & 1,1000 & 1,2100 & 1,3310 & 1,4641 \\
\hline Auxiliar de cozinha & & 1,0000 & 1,1000 & 1,2100 & 1,3310 & 1,4641 \\
\hline Copeiro & & 1,0000 & 1,1000 & 1,2100 & 1,3310 & 1,4641 \\
\hline Faxineiro & & 1,0000 & 1,1000 & 1,2100 & 1,3310 & 1,4641 \\
\hline Servente & & 1,0000 & 1,1000 & 1,2100 & 1,3310 & 1,4641 \\
\hline Serviços de manutenção & & 1,0000 & 1,1000 & 1,2100 & 1,3310 & 1,4641 \\
\hline Porteiro & \multirow{4}{*}{$2^{\circ}$ Nível } & 1,0092 & 1,1102 & 1,2212 & 1,3433 & 1,4776 \\
\hline Inspetor de alunos & & 1,0092 & 1,1606 & 1,3347 & 1,5349 & 1,7652 \\
\hline Cozinheiro & & 1,0092 & 1,1102 & 1,2212 & 1,3433 & 1,4776 \\
\hline Auxiliar administrativo & & 1,0092 & 1,1606 & 1,3347 & 1,5349 & 1,7652 \\
\hline Auxiliar & \multirow{6}{*}{$3^{\circ}$ Nível } & 1,0599 & 1,2189 & 1,4017 & 1,6120 & 1,8538 \\
\hline Auxiliar de Educação Infantil & & 1,0599 & 1,2189 & 1,4017 & 1,6120 & 1,8538 \\
\hline Auxiliar Ensino Fundamental & & 1,0599 & 1,2189 & 1,4017 & 1,6120 & 1,8538 \\
\hline Auxiliar de Ensino Médio & & 1,0599 & 1,2189 & 1,4017 & 1,6120 & 1,8538 \\
\hline Assis & & & 1,2189 & 1,4017 & 1,61 & 8538 \\
\hline Coordena & & 1,0599 & 1,2189 & 1,4017 & 1,6120 & 1,8538 \\
\hline Secretária escolar & \multirow{2}{*}{$4^{\circ}$ Nível } & 1,0772 & 1,3465 & 1,6831 & 2,1039 & 2,6299 \\
\hline Gerente & & 1,0772 & 1,4004 & 1,8205 & 2,3666 & 3,0766 \\
\hline Coordena & \multirow{6}{*}{$5^{\mathrm{o}}$ Nível } & & 2,6959 & 3,5046 & & 5,9229 \\
\hline Coordenador de área & & 2,0738 & 2,6959 & 3,5046 & 4,5560 & 5,9229 \\
\hline Orientador educacional & & 2,0738 & 2,5922 & 3,2402 & 4,0503 & 5,0629 \\
\hline Nutricionista & & 2,0738 & 2,5922 & 3,2402 & 4,0503 & 5,0629 \\
\hline Psicólogo & & 2,0738 & 2,5922 & 3,2402 & 4,0503 & 5,0629 \\
\hline Biblio & & 2,0738 & 2,5922 & 3,2402 & 4,0503 & 5,0629 \\
\hline Diret & \multirow{6}{*}{$6^{\text {o Nível }}$} & & & 3,8940 & 5,0623 & 6,5809 \\
\hline Diretor administrativo & & 2,3042 & 2,9954 & 3,8940 & 5,0623 & 6,5809 \\
\hline Diretor financeiro & & 2,3042 & 2,9954 & 3,8940 & 5,0623 & 6,5809 \\
\hline Diretor comercial & & 2,3042 & 2,9954 & 3,8940 & 5,0623 & 6,5809 \\
\hline Diretor geral & & 2,3042 & 2,9954 & 3,8941 & 5,0623 & 6,5809 \\
\hline Vice-diretor & & 2,3042 & 2,9954 & 3,8941 & 5,0623 & 6,5809 \\
\hline
\end{tabular}

Fonte: Os autores

Deste modo, estabelecendo-se o menor ou o maior valor de remuneração que a instituição de ensino deseja pagar a seus colaboradores, basta multiplicá-lo ou dividi-lo respectivamente pelos Fatores Finais de Remuneração (Tabela 5) para determinar-se o valor de todos os demais salários da instituição educacional, obtendo-se assim uma tabela de estrutura salarial. Para a melhor compreensão do exposto, seguem os exemplos abaixo:

Exemplo 1: Caso o menor salário que a instituição esteja disposta a pagar seja o valor do piso estipulado na CCT da SAAERJ para o $1^{\circ}$ nível no valor de $\mathrm{R} \$ 1.042,93$, os demais salários ficariam conforme a Tabela 6. 
Tabela 6: Valores salariais mínimos em reais para os cargos escolares da CCT 2018/2019 do SAAERJ

\begin{tabular}{|c|c|c|c|c|c|c|}
\hline Cargo & $\begin{array}{c}\text { Nível } \\
\text { na } \\
\text { CCT }\end{array}$ & $\begin{array}{c}\text { Trainee } \\
\mathrm{R} \$\end{array}$ & $\begin{array}{c}\text { Júnior } \\
\mathrm{R} \$\end{array}$ & $\begin{array}{l}\text { Pleno } \\
\text { R\$ }\end{array}$ & $\begin{array}{c}\text { Sênior } \\
\mathrm{R} \$\end{array}$ & $\begin{array}{c}\text { Master } \\
\mathrm{R} \$\end{array}$ \\
\hline Auxiliar de serviç & & $1.042,93$ & $1.147,22$ & $1.261,94$ & $1.388,13$ & $1.526,94$ \\
\hline Auxiliar de cozir & & $1.042,93$ & $1.147,23$ & $1.261,95$ & $1.388,14$ & $1.526,96$ \\
\hline Copeiro & $1^{o}$ & $1.042,93$ & $1.147,22$ & $1.261,94$ & $1.388,14$ & $1.526,95$ \\
\hline Faxineiro & Nível & $1.042,93$ & $1.147,23$ & $1.261,94$ & $1.388,14$ & $1.526,96$ \\
\hline Servente & & $1.042,93$ & $1.147,23$ & $1.261,94$ & $1.388,14$ & $1.526,96$ \\
\hline Serviços de manut & & $1.042,93$ & $1.147,23$ & $1.261,94$ & $1.388,14$ & $1.526,95$ \\
\hline Porteiro & & $1.052,56$ & $1.157,82$ & $1.273,60$ & $1.400,96$ & $1.541,05$ \\
\hline Inspetor de alunos & $2^{\mathrm{o}}$ & $1.052,56$ & $1.210,44$ & $1.392,01$ & $1.600,81$ & $1.840,93$ \\
\hline Cozinheiro & Nível & $1.052,56$ & & 1.27 & 1.40 & $1.541,05$ \\
\hline Auxiliar administrativo & & $1.052,56$ & $1.210,44$ & $1.392,01$ & $1.600,81$ & $1.840,94$ \\
\hline Auxilia & & $1.105,42$ & $1.271,23$ & $1.461,91$ & $1.681,19$ & $1.933,37$ \\
\hline Auxi & & $1.105,42$ & $1.271,24$ & $1.461,92$ & 1.68 & 1.9 \\
\hline Auxiliar de Ensino I & $3^{\mathrm{o}}$ & $1.105,42$ & $1.271,24$ & $1.461,92$ & $1.681,20$ & $1.933,38$ \\
\hline ar de Ensino Médio & Nível & $1.105,42$ & & $1.461,92$ & $1.681,20$ & $1.933,38$ \\
\hline didi to & & & & $1.461,92$ & & 39 \\
\hline Coorc & & $1.105,42$ & $1.271,24$ & $1.461,92$ & $1.681,20$ & $1.933,39$ \\
\hline irosonlor & $4^{\circ}$ & $1.123,44$ & $1.404,30$ & $1.755,38$ & $2.194,23$ & $2.742,79$ \\
\hline Gere & Jíve & $1.123,44$ & $1.460,47$ & $1.898,61$ & $2.468,19$ & $3.208,65$ \\
\hline $\mathrm{CoO}$ & & & & $3.655,10$ & & \\
\hline $\mathrm{Coc}$ & & & & 3.6 & & 12 \\
\hline educacional & $5^{\circ}$ & $2.162,78$ & $2.703,48$ & $3.379,34$ & $4.224,18$ & $5.280,24$ \\
\hline onista & Nível & $2.162,78$ & $2.703,47$ & $3.379,33$ & $4.224,16$ & $5.280,20$ \\
\hline Psicólogo & & $2.162,78$ & $2.703,47$ & $3.379,34$ & $4.224,18$ & $5.280,23$ \\
\hline Bibli & & $2.162,78$ & $2.703,48$ & $3.379,35$ & $4.224,20$ & $5.280,24$ \\
\hline Dire & & & & $4.061,22$ & & \\
\hline Diret & & 2.40 & 3.12 & $4.061,22$ & $5.279,58$ & $6.863,46$ \\
\hline Diretor & 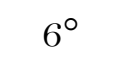 & $2.403,09$ & $3.124,02$ & $4.061,22$ & $5.279,59$ & $6.863,46$ \\
\hline Diretor comercial & Nível & $2.403,09$ & $3.124,02$ & $4.061,22$ & $5.279,59$ & $6.863,46$ \\
\hline Diretor geral & & $2.403,09$ & $3.124,02$ & $4.061,22$ & $5.279,59$ & $6.863,47$ \\
\hline Vice-diretor & & $2.403,09$ & $3.124,02$ & $4.061,22$ & $5.279,59$ & $6.863,47$ \\
\hline
\end{tabular}

Fonte: Os autores

Analisando a primeira coluna da Tabela 6, pode-se notar que os valores nela contidos refletem o piso salarial mínimo da CCT do SAAERJ para os cargos da administração escolar estabelecidos na Tabela 1.

Exemplo 2: Caso o menor salário da instituição seja $\mathrm{R} \$ 1.200,00$, a remuneração de um diretor Master (com mais de oito anos de experiência) seria $\mathrm{R} \$ 7.897,08$ ( $\mathrm{R} \$ 1.200,00 \mathrm{x}$ $6,5809)$ e assim por diante.

Ressalta-se que os Fatores Finais de Remuneração apresentados até aqui foram baseados no método de escalonamento simultâneo (CHIAVENATO, 2014), o qual agrupa cargos similares nas mesmas faixas salariais; e nas diferenças entre faixas salariais determinadas pela CCT da SAAERJ. 
Como uma variante desta metodologia, para a utilização das CCT dos Auxiliares da Administração Escolar de outros estados brasileiros, as quais não estabelecem cargos, mas apenas o piso mínimo que deve ser pago pela instituição, os Fatores Mínimos de Remuneração podem ser obtidos levando-se em consideração apenas as médias salariais praticadas no mercado para quaisquer cargos que a instituição determinar. Para efeito de praticidade neste trabalho, utilizando-se os cargos já estabelecidos na CCT da SAAERJ, o cálculo é feito dividindo-se os valores da primeira coluna da Tabela 2. Média salarial praticada no mercado para os cargos da CCT da SAAERJ, pelo piso mínimo estabelecido na CCT dos Auxiliares da Administração Escolar do Estado em questão. Observe-se que onde qualquer fator for inferior a 1,0000, o mesmo deverá ser igualado à 1,0000 (para não se incorrer no risco de pagar abaixo do piso mínimo), conforme a Tabela 7. Nesta tabela, utilizou-se o piso mínimo da CCT do Sindicado dos Auxiliares da Administração Escolar do Estado de São Paulo (SAAESP) 2018/2019, no valor de R\$1.185,67.

Tabela 7: Fatores mínimos de remuneração de cargos escolares baseados no piso mínimo da CCT da SAAESP

\begin{tabular}{lr}
\hline Cargo & Fator mínimo de remuneração \\
\hline Auxiliar de serviços gerais & $(0,7499) 1,0000$ \\
Auxiliar de cozinha & $(0,8487) 1,0000$ \\
Copeiro & $(0,8196) 1,0000$ \\
Faxineiro & $(0,8118) 1,0000$ \\
Servente & $(0,8118) 1,0000$ \\
Serviços de conservação e manutenção & $(0,9428) 1,0000$ \\
\hline Porteiro & $(0,8632) 1,0000$ \\
Inspetor de alunos & $(0,8967) 1,0000$ \\
Cozinheiro & $(0,9994) 1,0000$ \\
Auxiliar administrativo & $(0,8291) 1,0000$ \\
\hline Auxiliar de secretaria & $(0,8212) 1,0000$ \\
Auxiliar de Educação Infantil & $(0,8129) 1,0000$ \\
Auxiliar de Ensino Fundamental & $(0,8129) 1,0000$ \\
Auxiliar de Ensino Médio & $(0,8129) 1,0000$ \\
Assistente de biblioteca & $(0,9139) 1,0000$ \\
Coordenador de turno & $(0,9400) 1,0000$ \\
\hline Secretária escolar & $(0,8260) 1,0000$ \\
Gerente & $(0,8199) 1,0000$ \\
\hline Coordenador pedagógico & 1,7979 \\
Coordenador de área & 1,7979 \\
Orientador educacional & 1,1491 \\
Nutricionista & 1,3666 \\
Psicólogo & 1,5553 \\
Bibliotecário & 1,1038 \\
\hline Diretor pedagógico & 2,3304 \\
Diretor administrativo & 4,5892 \\
Diretor financeiro & 6,1363 \\
Diretor comercial & 5,8039 \\
Diretor geral & 2,9245 \\
Vice-diretor & 2,9245 \\
\hline & \\
\hline
\end{tabular}


Como visto anteriormente, estabelecidos os Fatores mínimos de Remuneração (Tabela 7), basta multiplicá-los pelos os Fatores de Experiência (Tabela 3), para obtermos os "Fatores Finais de Remuneração". Do mesmo modo, estabelecendo-se o menor ou o maior valor de remuneração que a instituição de ensino deseja pagar a seus colaboradores, basta multiplicá-lo ou dividi-lo respectivamente pelos Fatores Finais de Remuneração para determinar o valor de todos os demais salários da instituição educacional, obtendo-se, assim, uma tabela de estrutura salarial.

A mesma metodologia pode ainda ser utilizada para o estabelecimento do cálculo da hora-aula do quadro docente, não sendo necessário calcular-se os Fatores Finais de Remuneração. Utilizando-se os valores mínimos para hora-aula da CCT do Sindicato dos Professores (SINPRO) Niterói e Região 2018/2019, obtemos a Tabela 8.

Tabela 8: Valor mínimo da hora-aula em reais pela CCT do SINPRO Niterói e Região 2018/2019

\begin{tabular}{lr}
\hline Cargo & Valor da Hora-aula $(\mathrm{R} \$)$ \\
\hline Professor Ensino Infantil (EI) / Ensino Fundamental (EF) 1 & 12,93 \\
Professor Ensino Fundamental (EF) 2 & 19,63 \\
Professor Ensino Médio (EM) & 21,09 \\
\hline
\end{tabular}

Fonte: Os autores

Para o cálculo dos Fatores de Experiência dos professores, foram coletadas as médias salariais de mercado com base em março/2019, considerando uma empresa de pequeno porte, ou seja, aquela com receita bruta anual até 10,5 milhões de reais e com menos de 500 funcionário. A fonte utilizada para o cálculo das médias salariais foram os salários pretendidos nos currículos cadastrados no BNE e as contribuições salariais do Salário BR nos últimos doze meses (Tabela 9).

Tabela 9: Média salarial mensal em reais praticada no mercado para os cargos de professores

\begin{tabular}{lcccccr}
\hline Cargo & $\begin{array}{c}\text { Trainee } \\
(\mathrm{R} \$)\end{array}$ & $\begin{array}{c}\text { Júnior } \\
(\mathrm{R} \$)\end{array}$ & $\begin{array}{c}\text { Pleno } \\
(\mathrm{R} \$)\end{array}$ & $\begin{array}{c}\text { Senior } \\
(\mathrm{R} \$)\end{array}$ & $\begin{array}{c}\text { Master } \\
(\mathrm{R} \$)\end{array}$ & $\begin{array}{c}\text { Amostragem } \\
\text { pesquisada }\end{array}$ \\
\hline Professor EI / EF 1 & $1.047,11$ & $1.308,89$ & $1.636,11$ & $2.045,14$ & $2.556,43$ & 11.140 \\
Professor EF2 & $1.201,78$ & $1.502,22$ & $1.877,78$ & $2.347,23$ & $2.934,04$ & 4.414 \\
Professor EM & $1.307,32$ & $1.634,15$ & $2.042,69$ & $2.553,36$ & $3.191,70$ & 1.628 \\
\hline \multicolumn{7}{c}{ Fonte: Os autores }
\end{tabular}

Analisando-se os dados obtidos na tabela acima, mais uma vez podemos concluir que há um padrão matemático de aumento da remuneração de acordo com os anos de experiência do professor. Dividindo-se os valores das segunda (Júnior), terceira (Pleno), quarta (Master) e quinta (Sênior) colunas, pelo valor da primeira coluna (Trainee), obtemos os "Fatores de Experiência” para o quadro docente (Tabela 10). 
Tabela 10: Fatores de Experiência dos cargos de professores

\begin{tabular}{lccccc}
\hline Cargo & Trainee & Júnior & Pleno & Sênior & Master \\
\hline Professor EI / EF 1 & 1,0000 & 1,2500 & 1,5625 & 1,9531 & 2,4414 \\
Professor EF2 & 1,0000 & 1,2500 & 1,5625 & 1,9531 & 2,4414 \\
Professor EM & 1,0000 & 1,2500 & 1,5625 & 1,9531 & 2,4414 \\
\hline \multicolumn{7}{c}{ Fonte: Os autores }
\end{tabular}

Encontrados os Fatores de Experiência (Tabela 8), basta multiplicá-los pelo valor da hora-aula do cargo em questão (Tabela 11).

Tabela 11: Valor da hora-aula em Reais de professor baseados na CCT da SAAERJ, considerando-se os fatores de experiência praticados pelo mercado

\begin{tabular}{lcccrr}
\hline Cargo & $\begin{array}{c}\text { Trainee } \\
(\mathrm{R} \$)\end{array}$ & $\begin{array}{c}\text { Júnior } \\
(\mathrm{R} \$)\end{array}$ & $\begin{array}{c}\text { Pleno } \\
(\mathrm{R} \$)\end{array}$ & Sênior $(\mathrm{R} \$)$ & Master $(\mathrm{R} \$)$ \\
\hline Professor EI / EF1 & 12,93 & 16,16 & 20,20 & 25,25 & 31,57 \\
Professor EF2 & 19,63 & 24,54 & 30,67 & 38,34 & 47,92 \\
Professor EM & 21,09 & 26,36 & 32,95 & 41,19 & 51,49 \\
\hline \multicolumn{5}{c}{ Fonte: Os autores }
\end{tabular}

Convém ressaltar que, para efeito de cálculo da remuneração mensal do professor, o mês é constituído de quatro semanas e meia, de acordo com o artigo 320, $\$ 1^{\circ}$ da Consolidação das Leis do Trabalho (CLT), cujo resultado deverá ser acrescido de 1/6, a título de repouso semanal remunerado, conforme súmula 351, do Tribunal Superior do Trabalho (TST, 2003).

Apresentando a metodologia de modo resumido, temos que por meio da apuração de Fatores Mínimos de Remuneração extraídos das Convenções Coletivas de Trabalho dos Sindicatos dos Auxiliares da Administração Escolar (SAAE) e dos Sindicatos de Professores (SINPRO) e da apuração de Fatores de Experiência extraídos das médias salariais de mercado apurou-se Fatores Finais de Remuneração. Ao multiplicar-se os Fatores Finais de Remuneração pelo valor mínimo ou máximo em reais que a instituição está disposta a pagar aos seus colaboradores, apura-se a estrutura salarial da instituição.

É certo que a remuneração na rede pública não está associada ao desempenho dos professores, e sim ao tempo de serviço destes (BARBOSA FILHO; PESSOA, 2011), conforme a metodologia do plano de carreiras salariais aqui discutida. Desse modo, em um futuro, o desempenho dos professores também pode ser um item relevante na composição de seus salários, motivando-os cada vez mais na transmissão de tal energia aos seus alunos, apesar de ser um item subjetivo de difícil análise, necessitando, assim, mais estudos aprofundados sobre o tema. 


\section{Considerações finais}

Por meio de uma pesquisa documental foi possível criar uma metodologia para a elaboração da estrutura salarial de uma instituição de ensino. Esta considerou tanto as Convenções Coletivas de Trabalho dos Sindicatos dos Auxiliares da Administração Escolar (SAAE) e dos Sindicatos de Professores (SINPRO) quanto as médias salariais praticadas no mercado para o segmento em questão. Para a aplicação da metodologia em outras instituições, cargos podem ser acrescentados ou retirados da estrutura salarial, e fatores podem ser ajustados de acordo com a política interna da organização. A metodologia apresentada neste artigo representa uma base para que a organização estabeleça uma estrutura salarial justa e igualitária, levando-se em consideração o equilíbrio interno e externo da organização. Todos os demais direitos e benefícios estabelecidos pela Consolidação das Leis do Trabalho (CLT) (BRASIL, 1943) e nas Convenções Coletivas de Trabalho (CCT) devem ser assegurados. O aprofundamento desta pesquisa poderá conduzir ao aperfeiçoamento da metodologia aqui desenvolvida, tornando possível a elaboração de Planos de Cargos, Carreiras e Salários completos.

\section{Referências}

BANCO NACIONAL DE EMPREGOS (BNE). 2019. Disponível em: $<$ https://www.bne.com.br/>. Acesso em: 09 mar. 2019.

BARBOSA FILHO, F.H; PESSOA, S.A. A carreira de professor estadual no Brasil: os casos de São Paulo e Rio Grande do Sul. Revista de Administração Pública, v. 45, n. 4, p. 965-1001, 2011. DOI: https://doi.org/10.1590/s0034-76122011000400004

BBC NEWS. 2018. Salários altos, prestígio, apoio ao estudo: as lições dos países que tratam bem seus professores. Disponível em: <https://www.bbc.com/portuguese/geral-45680063>. Acesso em: 10 jan. 2020.

BRASIL. Decreto-Lei n. 5442, de 01 de maio de 1943. Aprova a Consolidação das Leis do Trabalho. Disponível em: <http://www.planalto.gov.br/ccivil_03/DecretoLei/Del5452compilado.htm>. Acesso em: 08 abr. 2019.

BRASIL. Constituição da República Federativa do Brasil de 1988. Brasília, DF: Presidência da República, [2016]. Disponível em: <http://www.planalto.gov.br/ccivil_03/constituicao/constituicao.htm>. Acesso em: 06 abr. 2019.

BRASIL. Lei n.13.005, de 25 de junho de 2014. Aprova o Plano Nacional de Educação - PNE e dá outras providências. Diário Oficial da União, Brasília, DF., 26 jun. 2014. Disponível em: <https://www.planalto.gov.br/ccivil_03/_ato2011-2014/2014/lei/113005.htm>. Acesso em: 10 abr. 2019.

CARROL, S. J. Business strategies and compensation systems. In: BAKIN, D.B.; GÔMEZMEJÍA, L.R. New perspectives on compensation. Englewood Cliffs: Prentice Hall, 1987.

CHIAVENATO, I. Recursos humanos. o capital humano das organizações. 3. ed. Rio de Janeiro: Elsevier, 2010. 
CHIAVENATO, I. Gestão de pessoas: o novo papel dos recursos humanos nas organizações. 4. ed. Barueri: Manole, 2014.

DRUCKER, P. Management, tasks, responsibilities, practices. New York: Harper and Row Publishers, 1974.

MELLO E SOUZA, A. Determinantes da aprendizagem em escolas municipais. Ensaio: Avaliação $e$ Políticas Públicas em Educação, v. 13, n. 49, p. 413-434, 2005. DOI: https://doi.org/10.1590/s0104-40362005000400002

MILKOVICK, G.T; BOUDREAU, J.W. Human resources management. New York: Richard D. Irwin, 1994.

PALAZZO, J.; GOMES, C.A. Plano de carreira e avaliação dos professores: encontros e desencontros. Ensaio: Avaliação e Políticas Públicas em Educação, v. 17, n. 63, p. 205-234, 2009. DOI: https://doi.org/10.1590/s0104-40362009000200003

PATTON, T. Pay. New York: Free Press, 1977.

PEREIRA, G.L.; ALVES, T. Contribuições da produção acadêmica recente sobre remuneração docente para discussão da Meta 17 do PNE. FINEDUCA - Revista de Financiamento da Educação, v. 5, n. 1, p. 1-21, 2015.

SALÁRIO BR. 2019. Pesquisa salarial no Brasil. Disponível em: <http://www.salariobr.com/>. Acesso em: 09 mar. 2019.

SILVA, M.L.L.; LEÃO, D.O. A gestão escolar democrática e o princípio de valorização e reconhecimento do trabalho do professor. Revista de Gestão e Avaliação Educacional, v. 7, n. 16, p. 77-90, 2018. DOI: https://doi.org/10.5902/2318133832901

SINDICATO DOS AUXILIARES DE ADMINISTRAÇÃO ESCOLAR DO ESTADO DO RIO DE JANEIRO (SAAERJ). 2019. CCT Estadão 2018-2019 SAAERJ. Disponível em: <http://saaerj.org.br/pdf/CCT-Estadao-2018-2019.PDF>. Acesso em: 01 mar. 2019.

SINDICATO DOS AUXILIARES DE ADMINISTRAÇÃO ESCOLAR DE SÃO PAULO (SAAESP). 2019. Convenção Coletiva de Trabalho 2018/2019 - Auxiliares de Administração Escolar no Ensino Básico. Disponível em: <http://www.saaesp.org.br/convencao-coletiva-de-trabalho20182019-auxiliares-de-administracao-escolar-no-ensino-basico>. Acesso em: 08 mar. 2019.

SINDICATO DOS PROFESSORES (SINPRO) NITERÓI E REGIÃO. 2019. SINEPE/RJ. Disponível em: <http://www.sineperj.org.br/admIN/upload/convencao/CCT20182019Nitero769i1.pdf>. Acesso em: 08 mar. 2019.

TRABALHA BRASIL. 2019. Média Salarial. Disponível em <https://www.trabalhabrasil.com.br/media-salarial>. Acesso em: 09 mar. 2019.

TRIBUNAL SUPERIOR DO TRABALHO (TST). 2003. Súmula 351. Professor - Repouso semanal remunerado. Disponível em: <http://www.tst.jus.br/sumulas>. Acesso em: 08 abr. 2019.

WALLACE, M.J. Sustaining success with alternative rewards. In: ROCK, M.L.; BERGER, L.A. The compensation handbook. New York: McGraw-Hill, 1991. DOI: https://doi.org/10.1002/9781118881255.ch1

WALLACE, M.J.; FAY, C.H. Compensation theory and practice. Boston: PWS-Kent, 1983. 